\title{
UTILIZATION OF INDUSTRIAL WASTE PRODUCTS IN THE PRODUCTION OF ASPHALT CONCRETE FOR ROAD CONSTRUCTION
}

\author{
OYEDEPO J. Olugbenga ${ }^{1 *}$
}

\section{Abstract}

The utilization of industrial waste products to produce asphalt concrete for road construction was investigated. Aggregates were partially replaced with aluminum slag (AS) and crushed ceramic tiles (CCT) at 10\%, 20\%, 30\%, 40\%, and 50\% by weight. Physical tests were performed on the aggregates, while a flash and fire point test as well as penetration tests were carried out on the bitumen. Similarly, Marshall stability tests were conducted on cylindrical specimens of the asphalt concrete. The average values of 18.88 and 30.69 obtained for the aggregate impact value (AIV) and aggregate crushing value (ACV) were satisfactory for road surfacing when compared with the specification. Marshall stability values of $10.84 \mathrm{KN}, 4.27 \mathrm{KN}$, and 3.21 KN respectively were obtained with $30 \%, 20 \%$, and $50 \%$ partial replacements with AS. The percentages were suitable for heavy, medium and light traffic when compared with the Marshall design criteria provided by the Asphalt Institute. The use of aluminum slag and crushed ceramic tile could reduce the large volume of industrial waste and the cost of pavement construction and maintenance.

\section{INTRODUCTION}

Urbanization and civilization produce huge amounts of non-biodegradable waste. which poses serious disposal issues and environmental pollution, while the construction and maintenance of more roads consume large amounts of materials such as aggregates. The scarcity of naturally occurring materials such as the aggregates and bitumen used to produce asphaltic concrete has increased the cost of road construction, which necessitates a search for alternative and sustainable materials. The availability of huge amounts of industrial waste products such as ceramic tiles, steel slag, and aluminum slag among others, especially in developing countries like Nigeria, can be reused in the production of asphalt concrete. This could solve the waste disposal problem and offer the benefits of resource recovery, thus leading to the conversion of waste to wealth.

\section{Address}

1 Civil Engineering Department, Federal University of Technology, Akure, Nigeria

* Corresponding author: ojoyedepo@futa.edu.ng

\section{Key words}

- Non-biodegradable waste,

- Asphalt concrete,

- Marshall stability,

- Pavement construction,

- Maintenance. 
aggregates in asphalt could not only be cost effective, but could also be good from an environmental point of view. This study focuses on producing asphalt of an acceptable strength with crushed ceramic tile as a partial replacement of fine aggregates and aluminum slag as a partial replacement of coarse aggregates.

\section{REVIEW OF PAST STUDIES}

The term "hot-mix asphalt" (HMA) is used generically to include many different types of mixtures of aggregates and asphalt cement that are produced at an elevated temperature in an asphalt plant. Most commonly, HMA is divided into three different types of mix, i.e, densely-graded, open-graded, and gap-graded, which are primarily sorted according to the gradation of the aggregates used in the mix, see Table 1. However, the growing concern for resource depletion and global pollution has challenged many engineers to seek and develop new materials that rely on renewable resources (Teo, 2005). Several researchers in material science and engineering have used locally available material to partially or fully replace these costly conventional materials in both concrete and asphalt mixtures (Oyedepo et al., 2015). These include the use of by-products and waste material in building construction. In developing countries, where abundant agricultural and industrial waste is discarded, waste can be used to replace conventional material in the construction industry. The use of unconventional materials will reduce the cost and maintenance of road construction, while serving as a means of disposal of such waste.

Nwaobakata and Agunwamba (2014), investigated the effects of palm kernel shell (PKS) ash as a filler on the mechanical properties of hot asphalt mixes. The results showed that the use of 3\% palm kernel ash improved fatigue and lowered susceptibility to moisture. The performance of palm kernel shells as coarse aggregates in road binder courses was examined by Ndoke (2006) with an emphasis on the strength of the asphalt concrete as given by the Marshall stability test and flow values. He recommended that $10 \%$ palm kernel shells (PKS) be added to partially replace coarse aggregates, which would be appropriate for use in heavily trafficked roads. Adewale $e t$ al. (2015) also recommended that graded PKS could be used as a partial replacement for coarse aggregates in a wearing course of up to $10 \%$ for heavily trafficked roads, $30-50 \%$ for medium trafficked roads, and a full replacement of $100 \%$ for very lightly trafficked rural roads.

Similarly, Farag (2015) evaluated the effectiveness of using steel slag aggregates (SSAs) in highway construction work; his results show that the Marshall stability for asphalt concrete mixtures with steel aggregates is $50 \%$ higher than the stability for asphalt concrete mixtures with crushed limestone. He affirmed that SSAs have a higher density than crushed limestone aggregates; thus it can resist rutting. Accordingly, Magdi and Faiza (2017) evaluated the suitability of SSAs as a substitute for natural aggregates in the production of hot mix asphalt for road construction. The results revealed that the addition of SSAs significantly improves the properties of hot mix asphalt. Ameri et al. (2013) carried out a laboratory evaluation of warm mix asphalt mixtures containing electric furnace slag and concluded that slag improved the Marshall stability of hot mix asphalt mixtures and their resistance to permanent deformation.

Other researchers such as $\mathrm{Wu}$ et al. (2007) and Wen et al. (2014) evaluated the possibility of using steel slag as an aggregate in stone mastic asphalt mixtures. They investigated the mechano-chemical and physical changes in steel slag through diffraction analysis, scanning electron microscopy, thermos-gravimetric analysis, and mercury porosimeter tests. Based on the experimental results, they concluded that steel slag can be used as an aggregate since it represents an alternative, cost-effective, and environmentally friendly source of aggregates.

Research on the use of ceramic tiles was conducted e.g. by Descheng et al. (2013), who studied the performance and thermal evaluation of incorporated waste ceramic aggregates in the wearing layer of an asphalt pavement using a finite-element method. A significant effect of the surface layer's conductivity on the temperatures (at the top and bottom positions of the middle layer) in asphalt pavement was found in a model simulation. They opined that the addition of $40 \%$ crushed ceramic waste aggregates can reduce the thermal conductivity of asphalt mixtures, which has proven to be helpful in reducing the temperature gradient of a pavement. Also, Adebola et al. (2017) examined the utilization of construction waste tiles as a replacement of fine aggregates in concrete. They recommended a 5\% partial replacement of waste tiles for fine aggregates since they had a compressive strength value of $20.12 \mathrm{~N} / \mathrm{mm}^{2}$.

\section{MATERIALS AND METHODS}

Materials: The aluminum slag used was obtained from the Metallurgical and Materials Engineering Foundry Laboratory, Federal University of Technology Akure (FUTA) Nigeria; the broken tiles were sourced from construction sites on the FUTA Campus. Figure 1 shows a sample of the crushed broken tiles, while Figure 2 shows a sample of the aluminum slag. The bitumen penetration grade 60/70 was procured from KK Hassan Limited, Owo, Nigeria. Also, river sand free from deleterious materials, quarry dust, and other aggregates was sourced from a quarry in the town of Aaye the Ondo state of Nigeria.

Tab. 1: Types of Hot-Mix Asphalt

\begin{tabular}{|l|l|l|}
\hline Densely-Graded & Open-Graded & Gap-Graded \\
\hline Conventional & Porous friction course & Conventional gap-graded \\
Nominal maximum aggregate & & \\
Size usually 12.5 to $19 \mathrm{~mm}$ & Asphalt-treated permeable base & Stone-matrix asphalt (SMA) \\
$(0.5$ to $0.75 \mathrm{in})$ & & \\
Large stone & & \\
Nominal maximum aggregate & & \\
size usually between 25 and $37.5 \mathrm{~mm}$ & & \\
Sand 1.5 in $)$ & & \\
Nominal maximum aggregate & & \\
Size less than $9.5 \mathrm{~mm}(0.375 \mathrm{in})$. & & \\
\hline
\end{tabular}

Sources: Hot-Mix Asphalt Handbook 2000 


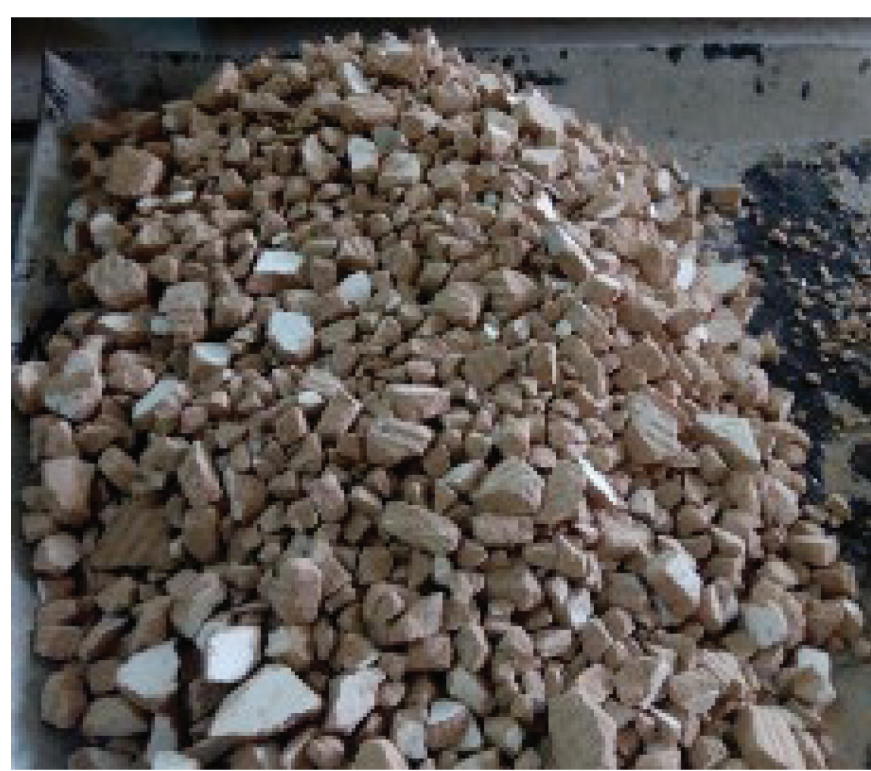

Fig. 1: Sample of Crushed Broken Tile

Methods: A sieve analysis was done in accordance with the American Standards for Testing and Materials (ASTM C136-01). It is primarily used to determine the grading of materials proposed for use as aggregates or that are being used as aggregates. Other standard tests such as the moisture content test for fine aggregates was conducted as specified by the British Standard (BS 812-109:1990); the aggregate impact value (AIV) and aggregate crushing value (ACV) tests for coarse aggregates in accordance with (BS 812 110:1990) were performed on the aggregates, aluminum slag, crushed ceramic tiles, and bitumen to ascertain their suitability. Similarly, a flash and fire point test (ASTM D92-01) and penetration test (ASTM D5-97) were performed on the bitumen. Figure 3 shows the experimental set up of the flash and fire point test

The coarse aggregates were partially replaced by aluminum slag and crushed ceramic tile at proportions of $10 \%, 20 \%, 30 \%, 40 \%$, and $50 \%$, respectively. A total of fifty samples composed of five samples each per mixture was produced. A Marshall stability test was performed on three cylindrical specimens made of the asphalt mixture that was produced for each partial replacement in accordance with the American Standard for Testing and Materials (ASTM D6927). Figure 4 shows the Marshall stability test apparatus used for the experiment, while Figure 5 is a sample of the cylindrical specimens used .

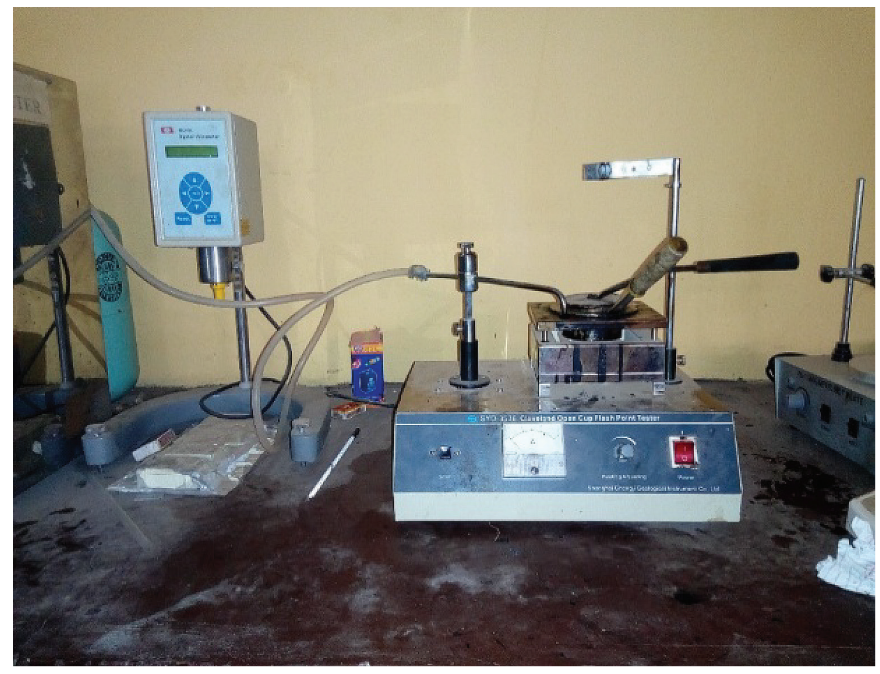

Fig. 3: Flash and Fire Point Test Experimental Set Up

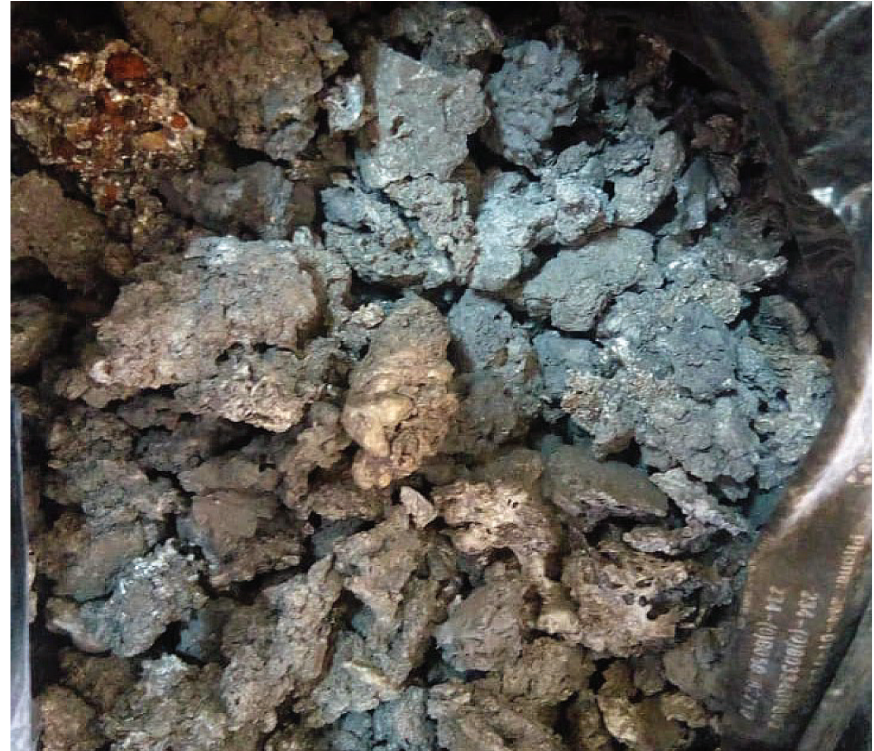

Fig. 2: Sample of the Aluminum Slag

\section{RESULTS AND DISCUSSION}

Table 2 is a summary of the results of the test for the moisture content of the various granular materials.

Tab. 2 Results of the Moisture Content Test

\begin{tabular}{|l|l|}
\hline Materials & Average Moisture Content (\%) \\
\hline Fine Aggregates & 1.01 \\
\hline Coarse Aggregates & 1.00 \\
\hline Aluminum Slag & 3.00 \\
\hline Crushed Broken Tiles & 3.05 \\
\hline
\end{tabular}

The results obtained show that the crushed broken tiles had the highest amount of the moisture content, while the coarse natural aggregates had the lowest amount of the moisture content. All the materials were within the specified value of not more than 5\% in accordance with the ASTM D2216-19.

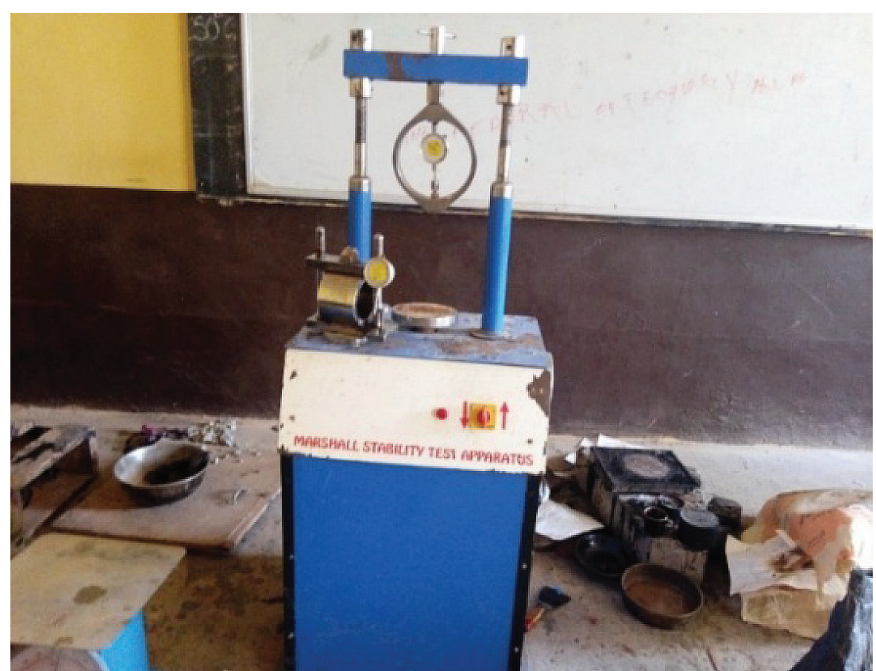

Fig. 4: Marshall Stability Test Apparatus 


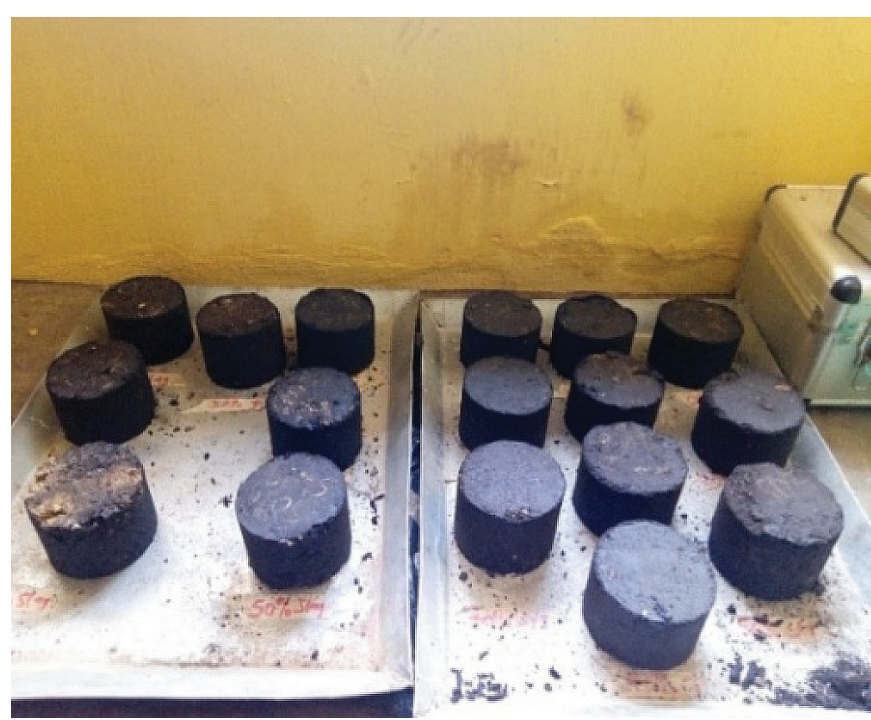

Fig. 5: Asphalt Mix Test Specimens

Tables 3 and 4 contain a summary of the values obtained from the $\mathrm{AIV}, \mathrm{ACV}$, flash and fire point tests and the penetration of bitumen tests.

Thus, the values obtained for the AIV and ACV tests are satisfactory for road surfacing or a wearing course.

According to ASTM D92-01, the flash point of $280{ }^{\circ} \mathrm{C}$ and the fire point of $320^{\circ} \mathrm{C}$ obtained represent satisfactory values since the minimum recommended value is $175^{\circ} \mathrm{C}$ for all bitumen grades. The average penetration value obtained was 66 , which shows that $60 / 70$ grade bitumen was used.

\subsection{Marshall Stability and Flow Test}

The results of the Marshall stability tests using aluminum slag as a partial replacement for coarse aggregates in asphalt concrete is shown in Table 5. Table 6 summarizes the current criteria for the Marshall mix design method, while Figs, 6 and 7 show the Marshall stability curve and flow respectively.

\subsubsection{Marshall Stability and Flow Using Aluminum Slag as a Partial Replacement}

Table 5 contains a summary of the test results using the aluminum slag (AS) as a partial replacement.

The experimental investigation revealed that the optimum value of 10.84 obtained with a $30 \%$ partial replacement with AS is suitable for heavy traffic $(8.006 \mathrm{KN})$; a $20 \%$ partial replacement is suitable for medium traffic $(5.338 \mathrm{KN})$; while a $50 \%$ partial replacement is
Tab. 3 Summary of the Test Results on the Aggregates

\begin{tabular}{|c|c|c|c|c|}
\hline \multicolumn{3}{|l|}{ Aggregate } & \multicolumn{2}{|c|}{ Recommended value } \\
\hline Test & AIV \% & $\mathrm{ACV} \%$ & AIV & Classification \\
\hline Sample 1 & 18.58 & 30.86 & $10-20 \%$ & Strong \\
\hline Sample 2 & 18.78 & 29.21 & $20-30 \%$ & $\begin{array}{l}\text { Satisfactory for road } \\
\text { surfacing }\end{array}$ \\
\hline Sample 3 & 19.28 & 32.00 & $>35 \%$ & Weak for road surfacing \\
\hline Average & 18.88 & 30.69 & & \\
\hline
\end{tabular}

Note: The minimum value of the ACV is 30 , which is recommended for bituminous macadam.

Tab. 4 Summary of Test Results on Bitumen

\begin{tabular}{|c|c|c|c|}
\hline \multicolumn{3}{|c|}{ Bitumen } \\
\hline & Flash Point ${ }^{\circ} \mathrm{C}$ & Fire Point $^{\circ} \mathrm{C}$ & Penetration \\
\hline & 284 & 327 & 65 \\
\hline & 280 & 320 & 66 \\
\hline & 275 & 315 & 67 \\
\hline Average & 280 & 320 & $\mathbf{6 6}$ \\
\hline
\end{tabular}

Tab. 5 Stability and Flow Results of the Asphalt Mix Using Aluminum Slag as a Partial Replacement

\begin{tabular}{|l|l|l|}
\hline Percentage Replacement (\%) & Flow $(\mathbf{m m})$ & Stability (kN) \\
\hline 0 & 11.84 & 8.24 \\
\hline 10 & 11.20 & 3.36 \\
\hline 20 & 10.24 & 7.55 \\
\hline 30 & 8.64 & 10.84 \\
\hline 40 & 7.74 & 8.24 \\
\hline 50 & 6.21 & 3.36 \\
\hline
\end{tabular}

adequate for light traffic (3.336 KN), in accordance with the Marshall design criteria provided by the Asphalt Institute (1997) as seen in Table 5. Also, the flow values obtained are suitable for light, medium, and heavy traffic when compared with the Marshall design criteria in Table 5.

\subsubsection{Marshall Stability and Flow Test Using Aluminum Slag and Crushed Ceramic Tiles as Replacements}

Table 7 presents the results of the Marshall stability test using aluminum slag (AS) as a partial replacement of coarse aggregates and crushed ceramic tiles (CCT) as a partial replacement of fine ag-

Tab. 6 Typical Marshall Design Criteria

\begin{tabular}{|c|c|c|c|c|c|c|}
\hline \multirow{2}{*}{ Mix Criteria } & \multicolumn{2}{|c|}{ Light traffic (less than $10^{4}$ ESALs) } & \multicolumn{2}{|c|}{ Medium Traffic $\left(10^{4}-10^{6}\right.$ ESALs } & \multicolumn{2}{|c|}{ Heavy Traffic (greater than $10^{6}$ ESALs) } \\
\hline & Min. & Max. & Min. & Max. & Min. & Max. \\
\hline $\begin{array}{l}\text { Compaction ( } 50 \text { blows on } \\
\text { each side of the specimen) }\end{array}$ & 35 & & 50 & & 75 & \\
\hline Stability (minimum) & $2224 \mathrm{~N}$ & & $3336 \mathrm{~N}$ & & $6672 \mathrm{~N}$ & \\
\hline Flow $(0.25 \mathrm{~mm})$ & 8 & 20 & 18 & & 8 & 16 \\
\hline Air voids content & 3 & 5 & 3 & 5 & 3 & 5 \\
\hline
\end{tabular}

${ }^{*}$ An ESAL is the Equivalent Single Axle Load; Source: Asphalt Institute (1997) 


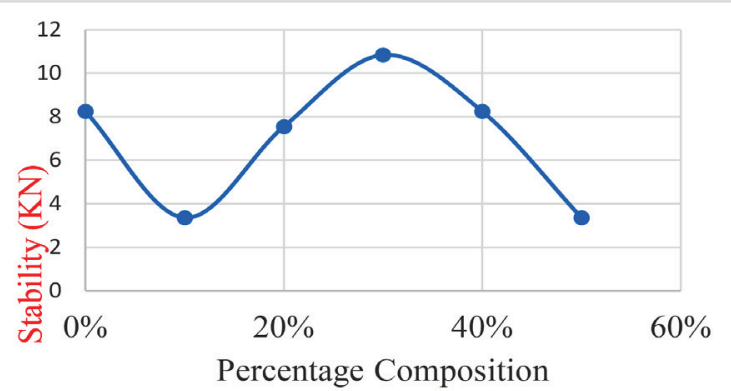

Fig. 6 Marshall Stability Curve For Asphaltic Concrete Using Aluminum Slag As a Partial Replacement For Aggregates

Tab. 7 Marshall Stability and Flow Results Using Aluminum Slag and Crushed Ceramic Tiles as Partial Replacements

\begin{tabular}{|l|l|l|}
\hline Percentage Replacement (\%) & Flow $(\mathbf{m m})$ & Stability $(\mathbf{k N})$ \\
\hline 0 & 11.84 & 8.24 \\
\hline 10 & 14.85 & 1.83 \\
\hline 20 & 13.63 & 4.27 \\
\hline 30 & 12.80 & 3.24 \\
\hline 40 & 12.80 & 5.19 \\
\hline 50 & 11.71 & 3.21 \\
\hline
\end{tabular}

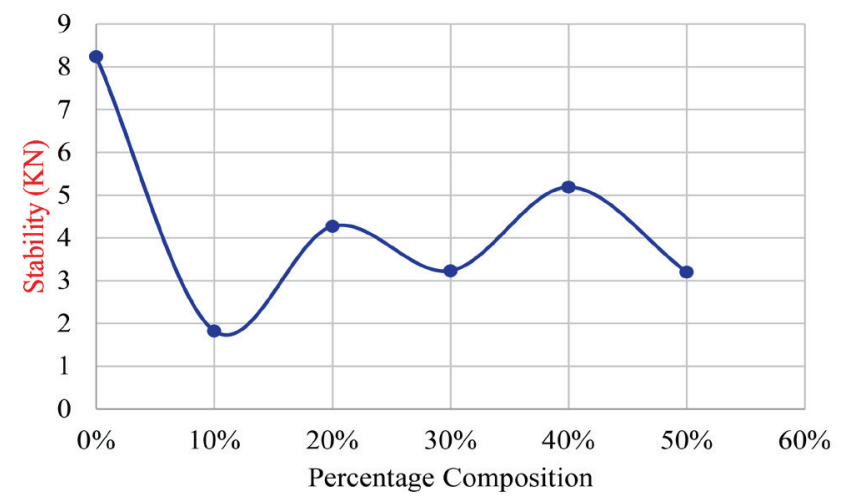

Fig. 8 Marshall Stability Curve for Asphaltic Concrete Using Aluminum Slag and Crushed Ceramic Tiles as a Partial Replacements for Aggregates

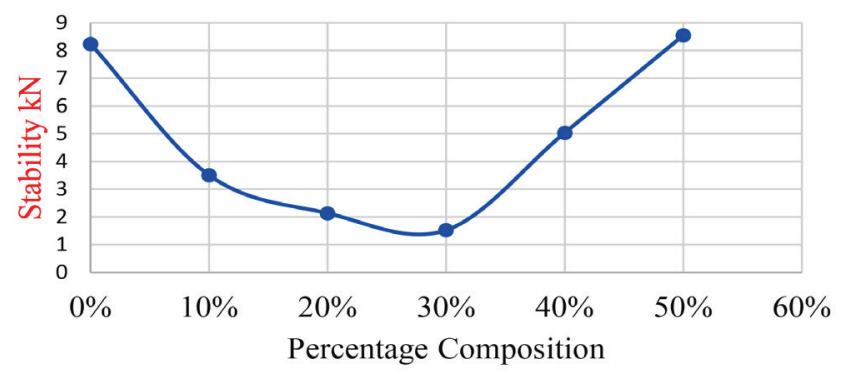

Fig. 10 Marshall Stability Curve for Asphalt Concrete Using Crushed Ceramic Tiles As a Partial Replacement for Aggregates

gregates. Also, Figures 8 and 9 show the Marshall stability curve and flow respectively.

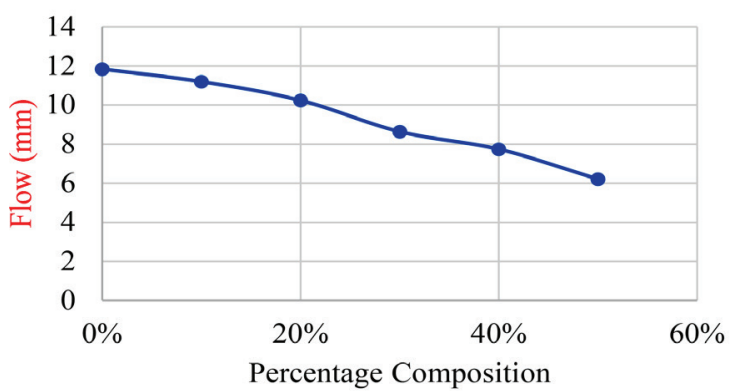

Fig. 7 Flow Curve For Asphaltic Concrete Using Aluminum Slag as a Partial Replacement For Aggregates

Tab. 8 Marshall Stability and Flow Results Using Crushed Ceramic Tiles as a Partial Replacement of Aggregates

\begin{tabular}{|l|l|l|}
\hline Percentage Replacement (\%) & Flow (mm) & Stability (kN) \\
\hline 0 & 11.84 & 8.24 \\
\hline 10 & 11.33 & 3.51 \\
\hline 20 & 11.20 & 2.14 \\
\hline 30 & 10.11 & 1.53 \\
\hline 40 & 2.24 & 5.04 \\
\hline 50 & 10.24 & 8.55 \\
\hline
\end{tabular}

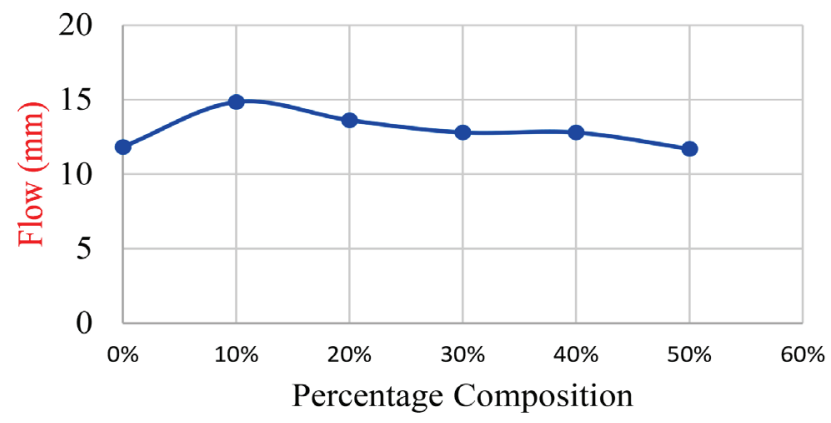

Fig. 9 Flow Curve for Asphalt Concrete Using Aluminum Slag and Crushed Ceramic Tiles as Partial Replacements for Aggregates

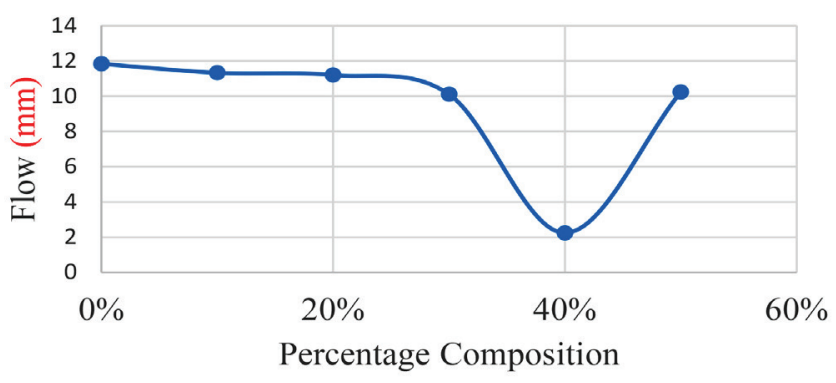

Fig. 11: Flow Curve for Asphalt Concrete Using Crushed Ceramic Tiles As a Partial Replacement For Aggregates

An optimum value of 5.19 was obtained for the Marshall stability value when aluminum slag was used as a partial replacement of the 
coarse aggregates with crushed broken tiles as a partial replacement of the fine aggregates with a $40 \%$ replacement; this indicates that the slag is suitable for light traffic $(3.336 \mathrm{KN})$, according to the Marshall design criteria as given in Table 6 .

The flow values obtained are suitable for light, medium, and heavy traffic in accordance with the criteria for the Marshall mix design method.

\subsubsection{Marshall Stability and Flow Using Crushed Ceramic Tiles as a Partial Replacement}

The summary of results for the Marshall stability test and flow using crushed ceramic tiles as a partial replacement of fine aggregates is presented in Tab. 8 and depicted graphically in Figures 10 and 11.

The experimental results, as depicted in Fig. 11 graph show that a $50 \%$ partial replacement of crushed ceramic tile (CCT) is suitable for heavy traffic $(8.006 \mathrm{kN})$, while it is adequate for light traffic $(3.336$ $\mathrm{kN}$ ) with $20 \%, 30 \%$ and $40 \%$ partial replacements of CCT, according to the Marshall design criteria provided by the Asphalt Institute (1997). The flow values obtained are suitable for light, medium, and heavy traffic.

\section{CONCLUSION}

The experimental investigation revealed that the optimum value of $10.84 \mathrm{KN}$ obtained as a $30 \%$ partial replacement with AS is suitable for heavy traffic $(10.84 \mathrm{kN})$; a $20 \%$ partial replacement is suitable for medium traffic $(4.27 \mathrm{kN})$; while a $50 \%$ partial replacement is adequate for light traffic $(3.21 \mathrm{kN})$ in accordance with the criteria for the Marshall mixture design method provided by the Asphalt Institute (1997). An optimum value of $5.04 \mathrm{kN}$ was obtained for the Marshall stability value when AS was used as a partial replacement of the coarse aggregates with crushed broken tiles as a partial replacement of the fine aggregates at a $40 \%$ level of replacement; this indicates that it is suitable for light traffic $(3.336 \mathrm{kN})$. Also, crushed ceramic tiles can be used as a suitable partial replacement of up to $10 \%$ for fine aggregates in asphalt concrete for light traffic roads, which gives a stability value of $3.511 \mathrm{kN}$, which is within the specifications for light traffic roads. The asphalt concrete produced when partially replaced with the aluminum slag and crushed ceramic tiles as recommended can be used for medium and light traffic roads as well as parking lots. Hence, the use of industrial waste will reduce the large volume of industrial waste in our environs and the cost of pavement construction. 


\section{REFERENCES}

Adebola, A. A. - Abimbola, K. R. - Familusi, A. O. (2017) Utilization of Construction Waste Tiles as a Replacement for Fine Aggregates in Concrete, Engineering, Technology \& Applied Science Research, Vol. 7, No. 3, pp. 1930-1933;

Adewale, O. - Abah - Uwakwe, R. (2015) Experimental Evaluation of the Effects of Partial Replacement of Coarse Aggregate with Graded Palm Kernel Shell in Asphaltic Wearing Course, International Journal of Civil and Structural Engineering, Vol. 6, No.1, pp. 90-104

Akinwumi, H. - Diwa, D. - Obianigwe N (2014) Effects of crude oil contamination on the index properties, strength and permeability of lateritic clay, International Journal of Applied Sciences and Engineering Research, 3(4),.816-824, DOI 10.6088/ijaser.030400007.

Ameri, M. - Hesame, S., - Goli, H. (2013) Laboratory evaluation of warm mix asphalt mixtures containing electric arc furnace slag, Construction and Building Materials Vol.4, No. 9, pp. 611-617;

Asphalt Institute (1997): Criteria for the Marshall Mixture Design Method;

ASTM C136-01: Standard Test Method for Sieve Analysis of Fine and Coarse Aggregates;

ASTM D92-01: Standard Test Method for Flash and Fire Points by Cleveland Open Cup;

ASTM D5-97: Standard Test Method for Penetration of Bituminous Materials;

ASTM D6927: Standard Test Method for Marshall Stability and Flow of Asphalt Mixtures;

ASTM D2216-19: Standard Test Methods for Laboratory Determination of Water (Moisture) Content of Soil and Rock Mass

Bhavin, K. V. - Bhatt, M. R. (2016): A study on effect of waste ceramic tiles in flexible pavement, International Journal of Advance Engineering and Research Development, Vol. 3, No.10, pp. 26-28;

BS 812-109:1990: Testing Aggregates, Method for Determination of Moisture Content;
BS 812 110:1990: Testing Aggregates, Method for Determination of Aggregate Crushing Value;

Descheng F. - Junyan Y. - Dongsheng W. (2013) Performance and thermal evaluation of incorporating waste ceramic aggregates in wearing layer of asphalt pavement, Journal of Materials in Civil Engineering, American Society of Civil Engineers, Vol. 25, No.7;

Farag K. (2015) Comparative study of using steel slag aggregates and crude limestone in asphaltic concrete mixtures, International Journal of Civil Engineering and Technology, Vol. 6 No. 3, pp. 73-82, Hot-Mix Asphalt Handbook 2000

Magdi, M. E. Z. - Faiza, O. A. K. (2017) Experimental Study of Steel Slag Used as Aggregate in Asphalt Mixture, American Journal of Construction and Building Materials, Vol.1 No. 1, pp.1218; Ndoke, P. N. (2006) Performance of Palm kernel shells as a partial replacement for coarse aggregate in asphalt concrete, Leonardo Electronic Journal of Practice and Technologies Vol. 5 , No. 6, pp. 145-152;

Nwaobakata S. C. and Agunwamba J. C. (2014) Effect of palm kernel shells ash as filler on the mechanical properties of hot mix asphalt, Archives of Applied Science Research, Vol. 6, No. 5, pp. 42-49;

Oyedepo, O. J. - Olanitori, L. M. - Olukanni, E. O. (2015) Investigation of palm kernel shell as partial replacement for aggregates in asphaltic concrete, Malaysian Journal of Civil Engineering, Vol. 27, No. 2, pp. 223-234;

Singh, P. - Singla R. K. (2015) Utilization of Waste Ceramic Tiles as Coarse Aggregate in Concrete, Journal of Multidisciplinary Engineering Science and Technology (JMEST), Vol. 2, No.11, pp. 3294-3300;

Teo, D. C. L. (2005) Utilization of solid waste oil palm shell in concrete production, Proceedings of the International Conference on Natural Resources and Environmental Management, Kuching, Sarawak, Malaysia, pp. 135-140;

Wu S., Xue Y., Ye Q. and Chen Y. (2007) Utilization of steel slag as aggregates for stone mastic asphalt (SMA) mixtures. Building and Environment, Elsevier. Vol. 42, No. 7, pp. 2580-2585. 